F. H. Clauser and Professor L. S. G. Kovásznay for their advice during the preparation of the manuscript.

${ }^{1}$ C. Walén, Arkiv. Mat. Astr. Fysik. 30A 15 (1944).

2 H. Hasimoto, Phys. Fluids 2, 337 (1959).

$\dagger$ For small values of Reynolds number this is possible by superposing $v_{+}, v_{-}$, and harmonic irrotational field.

${ }^{3}$ L. S. G. Kovásznay, Proc. Cambridge Phil. Soc. 44, 58 (1948).

\section{On Taylor Instability of Plane Surfaces*}

\section{S. G. BANKoFr}

California Institute of Technology, Pasadena, California (Received July 30, 1959)

A NUMBER of special results on combined Taylor and Helmholtz instability are readily derivable by imposing a constant velocity parallel to, and acceleration normal to, the interface such that the interfacial wave appears to be stationary. In this event the propagation equation is ${ }^{1}$

$$
\begin{array}{r}
k \rho(V-c)^{2} \operatorname{coth} k h+k \rho^{\prime}\left(V^{\prime}-c\right)^{2} \operatorname{coth} k h^{\prime} \\
=g\left(\rho-\rho^{\prime}\right)+\sigma k^{2},
\end{array}
$$

where $k$ is the wave number; $c$ is the wave speed; $\sigma$ is the interfacial tension; $\rho, V$, and $h$ are the density, velocity parallel to the interface, and depth of the lower fluid, the corresponding primed quantities referring to the upper fluid; and $g$ is the acceleration due to gravity. For fluids of infinite extent such that $V=V^{\prime}=\sigma=0$, this becomes

$$
n^{2}=k^{2} c^{2}=k g\left(\rho-\rho^{\prime}\right) /\left(\rho+\rho^{\prime}\right) .
$$

Considering $g$ to be a parameter, Eq. (2) is identical with Taylor's result, ${ }^{2}$ and the condition that $n^{2}$ be positive in order for waves of the prescribed type to be propagated is applicable here also. If $\sigma \neq 0, \mathrm{Eq}$. (1) yields the instability criterion given by Bellman and Pennington, ${ }^{3}$

$$
k<\left[g\left(\rho^{\prime}-\rho\right) / \sigma\right]^{3} .
$$

To obtain the effect of viscosity, we equate the rate of dissipation of energy in the wave to the rate of viscous working, ${ }^{1}$ arriving at a damping factor of the form exp $\left[-2 k^{2} t\left(\mu+\mu^{\prime}\right) /\left(\rho+\rho^{\prime}\right)\right]$, where $\mu$ and $\mu^{\prime}$ are the viscosities. Using Eq. (2), this leads directly to the instability criterion

$$
k<\left[-g\left(\rho^{2}-\rho^{\prime 2}\right) / 4\left(\mu+\mu^{\prime}\right)^{2}\right]^{\frac{3}{3}}
$$

which is identical with Bellman and Pennington's result, ${ }^{3}$ obtained by bounding the roots of $n$ by means of a comparison equation, except for a factor of $2^{3}$.

Some special results may be immediately set down. For example, combined Taylor and Helmholtz instability of two fluids of finite extent is governed by Eq. (1), which leads to imaginary values for $c$ if

$$
\begin{aligned}
-(V- & \left.V^{\prime}\right)^{2}<\left[g\left(\rho-\rho^{\prime}\right)+\sigma k^{2}\right] \\
\cdot & {\left[(k \rho \operatorname{coth} k h)^{-1}+\left(k \rho^{\prime} \operatorname{coth} k h^{\prime}\right)^{-1}\right] . }
\end{aligned}
$$

If $\sigma=0, V=V^{\prime}$, and $\rho^{\prime}>\rho, g$ must be negative in order for Eq. (5) to hold; so the extent of the fluid does not alter the threshold acceleration requirement for Taylor instability. However, the wavelength which grows most rapidly is affected. This will be the wavelength for which $n^{2}$ is a minimum. From Eq. (1) this is given by

$$
\begin{array}{r}
\frac{\left[g\left(\rho-\rho^{\prime}\right)+\sigma k^{3}\right]\left[\rho h \operatorname{csch}^{2} k h+\rho^{\prime} h^{\prime} \operatorname{csch}^{2} k h^{\prime}\right]}{\left[\rho \operatorname{coth} k h+\rho^{\prime} \operatorname{coth} k h^{\prime}\right]\left[g\left(\rho-\rho^{\prime}\right)+3 \sigma k^{2}\right]} \\
=-1 .
\end{array}
$$

For $\sigma=0$, as $h$ and $h^{\prime}$ approach infinity, $k$ also approaches infinity, indicating that the smallest wavelengths grow most rapidly, as noted by Taylor. However, for finite $h$ and $h^{\prime}$, the most rapid growth occurs at values of $k$ satisfying Eq. (6). As $h$ and $h^{\prime} \rightarrow \infty$, Eq. (6) reduces to

$$
k=\left[-g\left(\rho-\rho^{\prime}\right) / 3 \sigma\right]^{\frac{1}{2}},
$$

the result given previously for the most "dangerous" wave number. ${ }^{3}$

Thanks are due Professor M. S. Plesset for valuable discussions.

* This work was supported by the National Science Foundation.

${ }^{1}$ L. M. Milne-Thomson, Theoretical Hydrodynamics (The Macmillan Company, New York, 1955), third edition, pp. 390 and 552.

2 G. I. Taylor, Proc. Roy. Soc. (London) A201, 192 (1950).

${ }^{3} \mathrm{R}$. Bellman and R. H. Pennington, Quart. Appl. Math. $12,151(1954)$

\section{Anomalous Precursor Signals in Helium Shocks*}

\author{
H. G. Voorhies and F. R. Scort
}

John Jay Hopkins Laboratory for Pure and Applied Science, General Atomic Division of General Dynamics Corporation, San Diego, California (Received July 30, 1959)

$\mathrm{N}$ view of the interest in optical observations of highvelocity shocks and the reported observations of precursor signals in shock tubes, ${ }^{1}$ this letter is a report on the experimental observation of an anomalous optical precursor signal in an electromagnetically driven shock. ${ }^{2}$ The shock tube employed is similar to one reported by Josephson $^{3}$ in which a high-current conical discharge tube hydromagnetically implodes the gas at one end of a cylinder producing a hydrodynamic flow through a hollow electrode into the cylinder. The electrical system (see Fig. 1) was operated at $21 \mathrm{kv}$ with a peak current of $200000 \mathrm{amp}$ and at a base gas pressure of $150 \mu$; the gas used was $10 \%$ helium and $90 \%$ deuterium. The velocity of the shock at the observation position was $5 \mathrm{~cm} / \mu$ sec.

While the pressure broadening of the 5876-A line of helium was being observed at a position down the tube, precursor light was observed normal to the shock-tube axis well ahead of the time of arrival of the pressure front of the shock. The precursor line shape was measured with a 500-mm Jaco monochromator, with a 1P21 phototube as the detector. The precursor line width was $0.7 \mathrm{~A}$ 